\title{
Efficacy of light therapy for perinatal depression: a review
}

Shannon K Crowley ${ }^{1,2^{*}}$ and Shawn D Youngstedt ${ }^{1,2,3}$

\begin{abstract}
Perinatal depression is an important public health problem affecting $10 \%$ to $20 \%$ of childbearing women. Perinatal depression is associated with significant morbidity, and has enormous consequences for the wellbeing of the mother and child. During the perinatal period, treatment of depression, which could affect the mother and child during pregnancy and lactation, poses a complex problem for both mother and clinician. Bright light therapy may be an attractive treatment for perinatal depression because it is low cost, home-based, and has a much lower side effect profile than pharmacotherapy. The antidepressant effects of bright light are well established, and there are several rationales for expecting that bright light might also be efficacious for perinatal depression. This review describes these rationales, summarizes the available evidence on the efficacy of bright light therapy for perinatal depression, and discusses future directions for investigation of bright light therapy as a treatment for perinatal depression.
\end{abstract}

Keywords: Perinatal depression, Postpartum depression, Antepartum depression, Light therapy, Light

\section{Prevalence and treatment of perinatal depression}

Perinatal depression refers to depressive syndromes with onset during pregnancy or within 12 months after delivery [1]. Research findings suggest that between $10 \%$ and $20 \%$ of pregnant women experience a new episode of depression during pregnancy (antepartum depression) [2-4].

The prevalence of postpartum depression (PPD) is also estimated to be between $10 \%$ and $20 \%$ [3,5-7], with higher rates among women who had suffered from antepartum depression. Rates of perinatal depression seem to be particularly high in women with a prior history of depression, with estimates ranging from $25 \%$ to $50 \%$ [8]. Additional psychosocial factors which may increase a woman's risk for development of perinatal depression include single marital status, chronic illness, alcohol use during pregnancy, and lower socioeconomic status [9].

As during other times, risk of depression during the perinatal period may be influenced by genetic vulnerability. Additionally, the perinatal period may be a time of substantial vulnerability to affective illness due to the

\footnotetext{
* Correspondence: cornelsk@mailbox.sc.edu

'Department of Exercise Science, Arnold School of Public Health, University of South Carolina, Columbia, SC, USA

WJB Dorn VA Medical Center, Columbia, SC, USA

Full list of author information is available at the end of the article
}

rapid fluctuation in hormone levels during pregnancy, and more dramatically, during the postpartum period $[9,10]$. During pregnancy, depression and co-morbidities such as stress and anxiety appear to have a direct adverse biological impact on the intrauterine environment, and are linked to obstetric complications such as preterm labor, pre-eclampsia, and anemia, as well as adverse neonatal outcomes such as low birth weight, neonatal distress, and other neonatal abnormalities [11-13]. Longterm child health outcomes affected by antepartum depression include increased risk for neurodevelopmental disorders, motor difficulties, emotional and behavioral problems, and adolescent depression $[11,12,14]$.

Postnatally, maternal parenting behavior may be adversely affected by PPD, and this can have detrimental consequences on child behavioral development. Children of mothers who had suffered PPD are at increased risk for development of depression, anxiety disorders (including panic disorder), emotional maladjustment patterns, violent behavior, and other conduct disorders such as attention deficit hyperactivity disorder [15-18].

Treatment of depression during pregnancy and postpartum poses a complex problem for both mother and clinician. Many mothers feel guilty or fearful of their feelings during a time in which they assume they should 
be happy, thus refusing to acknowledge depressive symptoms and opting to 'suffer in silence'. Antidepressant use during pregnancy has been linked to multiple harmful effects to the infant, including persistent pulmonary hypertension, cardiac abnormalities, and neonatal withdrawal and toxicity [19-21].

Antidepressant use in mothers could also potentially harm the breastfeeding infants. A recent meta-analysis of 67 studies of antidepressant levels in breastfeeding infants found that out of 15 different antidepressants, all were detectable in breast milk at varying levels [22]. However, the available evidence on the effects of antidepressants during lactation on drug levels in the nursing infant is limited, and largely derived from short duration studies with small sample sizes. Studies have shown that antidepressant drugs or their metabolites are not always found in the child's serum, even though they may be detectable in breast milk [22,23]. For example, studies have found that levels of sertraline in infant serum were low to negligible in breastfeeding mother-infant pairs, in which the mothers were taking clinically relevant doses of sertraline [24,25], one of the most commonly prescribed antidepressants for breastfeeding mothers. However, it is unknown whether nursing infants might be sensitive to these low levels, particularly with chronic exposure. To date, there has been virtually no investigation of long-term child health outcomes from exposure to maternal antidepressant medication during breastfeeding. This is especially true for the modern selective serotonin reuptake inhibitors (SSRIs), as there are no studies with adequate follow-up of long-term child health outcomes [23,26]. It is noteworthy that no medication has been FDA-approved for PPD [11].

Notwithstanding the evidence of risks of antidepressant treatment for perinatal depression, many mental health providers have concluded that the detrimental effects of untreated maternal depression might pose an even greater threat to maternal and child health outcomes. There is some thought that adverse effects of antidepressant treatment on the nursing infant can be minimized by scaling back the dose [4], though this strategy might also reduce the efficacy of the drug for the mother.

Nonetheless, legitimate concerns about possible adverse effects of antidepressant medications on the developing fetus or newborn have led many women to refuse pharmacotherapy during pregnancy or while breastfeeding. For mothers who choose to take antidepressants during the postpartum period, many forgo the myriad benefits of breastfeeding in order to take antidepressants.

Psychotherapy is apparently an effective treatment for perinatal depression $[27,28]$. However, due to logistical issues, such as childcare arrangements and expenses, women with perinatal depression might also be less suitable for psychotherapy than other depressed individuals. Estimates indicate that only about $15 \%$ of women with PPD are receiving treatment [29]. Thus, alternative or adjuvant treatments for perinatal depression are needed.

\section{Rationale for bright light therapy of perinatal depression}

Bright light therapy may be an attractive treatment for perinatal depression because it is low cost, home-based, and has a much lower side effect profile than pharmacotherapy [30]. Moreover, the efficacy of bright light for other types of depression has been well established.

Particularly well-documented is the efficacy of bright light therapy for winter depression, for which bright light is generally regarded as the first line of treatment [31]. The utility of light for winter depression also has considerable intuitive appeal, as seasonal variation in mood are experienced my much of the population, and clearly attributed to fluctuations in light [32].

Less well recognized is that, in industrial societies, average levels of exposure to bright light ( $>1,000$ lux) average only about $1 \mathrm{~h}$ per day even in good weather conditions [33], and these levels might be inadequate for mood regulation in susceptible individuals. Moreover, accumulating evidence indicates that bright light might be equally efficacious for non-seasonal depression $[30,34,35]$, as well as other morbidities, including disturbed sleep [36,37], fatigue [38,39], and neuroendocrine abnormalities [40].

There are several factors related to the pathophysiology of depression and response to light which might make bright light especially suitable for perinatal depression. First, women with perinatal depression might receive very low light exposure. Pregnancy, particularly in late gestation, may make mobility difficult for some women, thus reducing time spent outdoors. After delivery, women may also experience lower levels of illumination, with increased time spent indoors caring for their infant who may often sleep during the day. Consistent with this notion are findings of seasonality of PPD, with increased risk of PPD associated with delivery during fall and early winter months [41,42] when daylight is of significantly shorter duration. Although a study by Wang et al. did not confirm differences in light exposure of postpartum women vs. matched control women who were not within 1 year postpartum [43], this remains a tenable hypothesis.

Second, there is some evidence that circadian malsynchronization is associated with depression and resynchronization is associated with the antidepressant effects of bright light [44]. There are reasons to suspect that women with perinatal depression might have circadian malsychronization. During pregnancy and postpartum, 
new mothers may spend a greater part of the day in dim light conditions in an effort to get sleep they may not be getting during the night. These conditions may be even more exaggerated in perinatal depression, where fatigue and anhedonia may severely limit daily activities. There has been limited investigation of the chronobiology of perinatal depression, though one recent study suggests that both amplitude and timing of melatonin secretion may be dysregulated in women with perinatal depression compared to non-depressed perinatal women [45].

Third, there is emerging evidence that impaired activation of serotonergically targeted circuits may be involved in the pathophysiology of PPD [46,47], which could be corrected with bright light treatment. For example, there is recent fMRI evidence that activation in these areas is abnormal in depressed $v s$. non-depressed mothers when responding to their newborns' cries $[48,49]$. Indeed, previous studies have implicated alterations in tryptophan (a serotonin precursor), estrogen, and hypothalamic pituitary adrenal (HPA) axis activity during the perinatal period as possible mediators of serotonin dysregulation [50-53]. Additionally, studies have found that genetic polymorphisms of the 5-HTT gene are associated with variations in PPD $[54,55]$, and increased vulnerability to development of depression in pregnancy and the postpartum [9]. Conversely, the SSRIs have been prescribed for perinatal depression [7], and have resulted in improvements in maternal role functioning in women with PPD [56,57].

There is some compelling evidence that the antidepressant effect of bright light therapy is mediated by serotonergic mechanisms. Studies have shown that the antidepressant effects of light therapy are reversed following tryptophan depletion [58]. Because tryptophan is a precursor to serotonin synthesis, tryptophan depletion reduces availability of serotonin in the brain, which in turn has been associated with emergence of depressive symptoms [59]. Using this established paradigm, recent work has illustrated that the mood lowering effect of tryptophan depletion in healthy women is completely blocked by carrying out the study in bright light $(3,000$ lux) vs. dim light (10 lux) [60]. Bright light therapy may provide a means to improve regulation of the serotonergic system in women with perinatal depression, and bright light therapy poses far less risk to the developing baby and newborn than current pharmacotherapy.

Fourth, there is evidence that perinatal depression may be influenced by alterations in estrogen, which could be corrected with bright light. The close relationship between estrogen and the serotonin system may provide some rationale for findings that some women have increased susceptibility to mood symptoms during periods of hormonal fluctuation, and that estrogen treatment has been shown to be effective in mood disorders, including postpartum depression $[61,62]$. It is clear from previous work that sex hormones such as estrogen and progesterone which rise greatly during pregnancy, and then show a sharp drop immediately after parturition - may play a role in the etiology of perinatal depression [9].

There is limited evidence that bright light therapy may be associated with stimulation of luteinizing hormone (LH), a gonadotropin involved in the production of estrogen [63]. The therapeutic benefit of light therapy for perinatal depression may therefore involve modulation of estrogen via stimulation of LH.

Fifth, bright light could alleviate co-morbidities of fatigue and sleep disturbance which might be especially problematic for perinatal depression, when the effects of sleep loss have consequences for both mother and baby. There appears to be an association between short sleep duration and adverse maternal and fetal outcomes [64-66], and limited evidence also suggests an association between sleep problems and maternal depression [67]. Indeed, fatigue and sleep disturbances are used diagnostically in the evaluation of perinatal depression, and are some of the most commonly reported symptoms in women with PPD [68]. Studies indicate that women with perinatal depression report substantially poorer sleep than matched healthy antepartum and postpartum women [69-72]. Evidence indicates that bright light therapy may decrease daytime fatigue partly via improvement of sleep [73], and/or improved daytime alertness $[37,38,74,75]$.

Notwithstanding the prevalence of perinatal depression and compelling rationales for its treatment with bright light, we are aware of only five studies of the effects of bright light therapy on perinatal depression. Three studies were randomized controlled trials and two were open trials. These studies will now be briefly reviewed.

\section{Studies of the efficacy of bright light therapy for antepartum depression}

The general characteristics of studies of bright light treatment for antepartum depression are summarized in Table 1. Results from an open trial by Oren and colleagues [76] showed a significant decrease (by 49\%) from baseline in Hamilton Depression Rating Scale (HDRS), Seasonal Affective Disorders Version (SIGH-SAD) after 3 weeks of 10,000 lux bright light therapy. The light was administered for $60 \mathrm{~min} /$ day, beginning within $10 \mathrm{~min}$ of awakening $(n=16)$. In a subset of participants $(n=7)$ who continued treatment for 5 weeks, mean scores on the SIGH-SAD decreased by $59 \%$ from baseline. Compliance was monitored by requiring subjects to call an answering machine daily to report their light use.

Expanding from this initial work, Epperson and colleagues conducted a randomized controlled trial in which 
Table 1 Studies of the efficacy of light therapy for perinatal depression

\begin{tabular}{|c|c|c|c|}
\hline \multicolumn{4}{|l|}{ Antepartum depression } \\
\hline & Oren et al. [76] & Epperson et al. [24] & Wirtz-Justice et al. [77] \\
\hline Subjects $(n)$ & 16 & 10 & 27 \\
\hline Treatment duration (weeks) & 3 & 5 & 5 \\
\hline Group randomization & No & Yes & Yes \\
\hline Time of light sessions & $\begin{array}{l}\text { Morning: beginning within } \\
10 \text { min of awakening }\end{array}$ & $\begin{array}{l}\text { Morning: beginning within } \\
10 \text { min of awakening }\end{array}$ & $\begin{array}{l}\text { Morning: beginning within } \\
10 \text { min of awakening }\end{array}$ \\
\hline Duration of light sessions (min) & 60 & 60 & 60 \\
\hline Intensity of light treatment (lux) & 10,000 & 7,000 & 7,000 \\
\hline Blind ratings & Yes & Yes & Yes \\
\hline Diagnosis of depression & SIGH-SAD $\geq 20$ & SIGH-SAD $\geq 20$ & SIGH-SAD $\geq 20$ \\
\hline Main outcome measure(s) & SIGH-SAD & SIGH-SAD & SIGH-SAD, HDRS \\
\hline \multicolumn{4}{|l|}{ Postpartum depression } \\
\hline & Corral et al. 2000 [78] & Corral et al. 2007 [79] & \\
\hline Subjects $(n)$ & 2 & 15 & \\
\hline Treatment duration (weeks) & 4 & 6 & \\
\hline Group randomization & No & Yes & \\
\hline Time of light sessions & $\begin{array}{l}\text { Morning: between 7:00 am } \\
\text { and 9:00 am }\end{array}$ & $\begin{array}{l}\text { Morning: between 7:00 am } \\
\text { and 9:00 am }\end{array}$ & \\
\hline Duration of light sessions (min) & 30 & 60 & \\
\hline Intensity of light treatment (lux) & 10,000 & 10,000 & \\
\hline Blind ratings & No & Yes & \\
\hline Diagnosis of depression & HDRS $=28,29$ & SIGH-SAD $\geq 15$ & \\
\hline Main outcome measure(s) & HDRS & SIGH-SAD & \\
\hline
\end{tabular}

HDRS = Hamilton Depression Rating Scale (Hamilton, 1967), SIGH-SAD = Structured Interview Guide for the Hamilton Depression Rating Scale, Seasonal Version (Williams, 1988).

participants with antepartum depression were assigned to either 7,000 lux (active, $n=5$ ) or 500 lux (placebo, $n=5$ ) light [24] for 5 weeks. The treatments were administered for $60 \mathrm{~min} /$ day, beginning within $10 \mathrm{~min}$ of awakening. To check compliance, subjects called the research clinic daily to $\log$ in the time of treatment. SIGH-SAD scores were reduced similarly by bright light (17.3) and the dimmer light (16.6).

Wirz-Justice and colleagues recently conducted a larger randomized controlled trial, in which 27 women with antepartum depression were randomized to 5 weeks of active treatment (7,000 lux bright light, $n=16)$, or placebo (70 lux dim red light, $n=11$ ). The treatments were administered for $60 \mathrm{~min} /$ day, beginning within 10 min of awakening [77]. Compliance was monitored with participant self-reported daily treatment logs. Participants receiving the bright light treatment showed significantly greater improvement in HDRS with Atypical Depression Supplement (SIGH-ADS) scores than those in the placebo treatment, and categorical analysis revealed that the response rate (HDRS $\geq 50 \%$ improvement) at week 5 was significantly greater for bright light $(81.3 \%)$ than for placebo $(45.5 \%)$. However, no significant differences between treatments were found in self- reported ratings of depression which included the Montgomery-Asberg Depression Rating Scale (MADRS) and the Beck depression Inventory.

\section{Studies of the efficacy of bright light therapy for postpartum depression}

General characteristics of studies of bright light treatment for postpartum depression are summarized in Table 1 . In an open trial by Corral et al. (2000) $(n=2)$, both participants showed substantial clinical improvement (75\% reduction in HDRS scores) following 4 weeks of 10,000 lux bright light treatment administered for 30 min between 7:00 am and 9:00 am [78]. However, a randomized controlled trial study by Corral et al., (2007) showed no differences between bright light treatment (10,000 lux, $n=10)$ and placebo (600 lux dim red light, $n=5$ ), administered for 6 weeks for $30 \mathrm{~min} /$ day between 7:00 am and 9:00 am. Both treatments elicited a 49\% reduction in SIGH-SAD scores [79]. Also, similar increases in SIGH-SAD scores were found following withdrawal of the treatments.

In this study, participants were asked to verbally report their treatment compliance weekly to the study physician. 


\section{Conclusions}

In summary, antidepressant effects of bright light are well established, and there are several rationales for expecting that bright light might also be efficacious for perinatal depression. In pregnant and/or new mothers, bright light treatment could potentially offset insufficient low levels of light exposure; pathological hormonal profiles; co-morbidities, including disturbed sleep and fatigue; and serotonergic dysregulation which has been linked to inadequate maternal behavior.

However, the efficacy of light therapy for perinatal depression has been reported in only five published studies, which have produced mixed results. These studies have had numerous limitations. First, only three of the five studies used a randomized controlled parallel group design. Second, the sample sizes have been small, perhaps due partly to difficulties in recruiting participants from this population. Third, participant adherence in these studies was only measured via participant self-reports. Adherence may be particularly problematic for this population, who have clear logistical obstacles to treatment. Fourth, studies have not addressed co-morbidities that light could alleviate, including anxiety [80,81], disturbed sleep, and fatigue.

Large randomized controlled trials are needed to determine whether bright light therapy elicits significant improvement in perinatal depression. For many women suffering from antepartum or postpartum depression, bright light is likely preferable to other types of treatment, but further research is needed to address questions about the feasibility of bright light treatment for these women. Comparative effectiveness trials would also fill a gap in existing literature, and may provide an important component of the overall treatment paradigm for women with perinatal depression. More targeted interventions may be feasible, perhaps with a mixed modalities treatment approach, for treating women with depression during pregnancy and/or postpartum. Additionally, further research is needed to determine potential mechanisms of the therapeutic effects of bright light therapy for perinatal depression.

\section{Competing interests}

The authors declare that they have no competing interest

\section{Authors' contributions}

SC and SY, contributed to the research, writing, and editing of this manuscript. Both authors read and approved the final manuscript.

\section{Acknowledgments}

This study was supported by the Veteran's Administration Merit Award and NIH R01 Grant Award \# HL095799.

\section{Author details}

${ }^{1}$ Department of Exercise Science, Arnold School of Public Health, University of South Carolina, Columbia, SC, USA. ${ }^{2}$ WJB Dorn VA Medical Center, Columbia, SC, USA. ${ }^{3}$ Department of Psychology, University of South Carolina, Columbia, SC, USA.
Received: 20 March 2012 Accepted: 20 March 2012

Published: 6 June 2012

\section{References}

1. Harald B, Gordon P: Meta-review of depressive subtyping models. J Affect Disorders 2011, :. Aug 31 [Epub ahead of print].

2. Breedlove G, Fryzelka D: Depression screening during pregnancy. J Midwifery Womens Health 2011, 56:18-25.

3. Gavin NI, Gaynes BN, Lohr KN, Meltzer-Brody S, Gartlehner G, Swinson T: Perinatal depression: a systematic review of prevalence and incidence. Obstet Gynecol 2005, 106:1071-1083.

4. Sit D, Perel JM, Wisniewski SR, Helsel JC, Luther JF, Wisner KL: Mother-infant antidepressant levels, maternal depression, and perinatal events. J Clin Psychiatry 2011, 72:994-1001.

5. Freeman MP: Postpartum depression treatment and breastfeeding. J Clin Psychiatry 2009, 70:e35

6. Mian Al: Depression in pregnancy and the postpartum period: balancing adverse effects of untreated illness with treatment risks. J Psychiatr Pract 2005, 11:389-396.

7. O'Hara MW: Postpartum depression: what we know. J Clin Psychol 2009, 65:1258-1269.

8. Marcus SM: Depression during pregnancy: rates, risks and consequencesMotherisk Update 2008. Can J Clin Pharmacol 2009, 16:e15-e22.

9. Meltzer-Brody S: New insights into perinatal depression: pathogenesis and treatment during pregnancy and postpartum. Dialogues Clin Neurosci 2011, 13:89-100.

10. Dennis $C L$, Ross $L$ : The clinical utility of maternal self-reported personal and familial psychiatric history in identifying women at risk for postpartum depression. Acta Obstet Gyneco/ Scand 2006, 85:1179-1185.

11. Alder J, Fink N, Bitzer J, Hosli I, Holzgreve W: Depression and anxiety during pregnancy: a risk factor for obstetric, fetal, and neonatal outcome? A critical review of the literature. J Matern Fetal Neonatal Med 2007, 20:189-289.

12. Bansil P, Kuklina EV, Meikle SF, Posner SF, Kourtis AP, Ellington SR, Jamieson DJ: Maternal and fetal outcomes among women with depression. J Womens Health 2010, 19:329-334.

13. Vesga-Lopez O, Blanco C, Keyes K, Olfson M, Grant BF, Hasin DS: Psychiatric disorders in pregnant and postpartum women in the United States. Arch Gen Psychiatry 2008, 65:805-815.

14. Hollins K: Consequences of antenatal mental health problems for child health and development. Curr Opin Obstet Gynecol 2007, 19:568-572.

15. Carter AS, Garity-Rokous FE, Chazan-Cohen R, Little C, Briggs-Gowan MJ: Maternal depression and comorbidity: predicting early parenting, attachment security, and toddler socialemotional problems and competencies. J Am Acad Child Adolesc Psychiatry 2001, 40:18-26.

16. Hay DF, Pawlby S, Angold A, Harold GT, Sharp D: Pathways to violence in the children of mothers who were depressed postpartum. Dev Psychol 2003, 39:1083-1094.

17. Sohr-Preston SL, Scaramella LV: Implications of timing of maternal depressive symptoms for early cognitive and language development. Clin Child Fam Psychol Rev 2006, 9:65-83.

18. Weissman MM, Pilowsky DJ, Wickramaratne PJ, Talati A, Wisniewski SR, Fava M, Hughes CW, Garber J, Malloy E, King CA, Cerda G, Sood AB, Alpert JE, Trivedi MH, Rush AJ: STAR*D- Child Team: Remissions in maternal depression and child psychopathology: a STAR*D- child report. JAMA 2006, 295:1389-1398.

19. Alwan S, Friedman J: Safety of selective serotonin reuptake inhibitors in pregnancy. CNS Drugs 2009, 23:493-509.

20. Gentile S: Serotonin reuptake inhibitor-induced perinatal complications. Pediatric Drugs 2007, 9:97-106.

21. Pearlstein T: Perinatal depression: treatment options and dilemmas. Psychiatry Neurosci 2008, 33:302-318.

22. Weissman AM, Levy BT, Hartz AJ, Bentler S, Donohue M, Ellingrod V, Wisner KL: Pooled analysis of antidepressant levels in lactating mothers, breast milk, and nursing infants. Am J Psychiatry 2004, 161:1066-1078.

23. Davanzo R, Copertino M, De Cunto A, Minen F, Ameddeo A: Antidepressant drugs and breastfeeding: A review of the literature. Breastfeed Med 2011, 6:89-98.

24. Epperson N, Czarkowski KA: Ward-O'Brien D, Weiss E, Gueorguieva R, Jatlow $P$, Anderson GM: Maternal sertraline treatment and serotonin transport in breast-feeding mother-infant pairs. Am J Psychiatry 2001, 158:1631-1637. 
25. Wisner $\mathrm{KL}$, Perel JM, Blumer J: Serum sertraline and N-desmethylsertraline levels in breast-feeding mother-infant pairs. Am J Psychiatry 1998, 155:690-692.

26. Field T: Breastfeeding and antidepressants. Infant Behav Dev 2008, 31:481-487.

27. Carter W, Grigoriadis S, Ravitz P, Ross LE: Conjoint IPT for postpartum depression: literature review and overview of a treatment manual. Am J Psychother 2010, 64:373-392.

28. Dimidjian S, Goodman S: Nonpharmacologic intervention and prevention strategies for depression during pregnancy and the postpartum. Clin Obstet Gynecol 2009, 52:498-515.

29. Ng RC, Hirata CK, Yeung W, Haller E, Finley PR: Pharmacologic treatment for postpartum depression: a systematic review. Pharmacotherapy 2010, 30:928-941

30. Terman M, Terman JS: Light therapy for seasonal and non-seasonal depression: efficacy, protocol, safety, and side effects. CNS Spectr 2005, 10:647-663.

31. Golden RN, Gaynes BN, Ekstrom RD, Hamer RM, Jacobsen FM, Suppes T, Wisner $\mathrm{KL}$, Nemeroff CB: The efficacy of light therapy in the treatment of mood disorders: a review and meta-analysis of the evidence. Am J Psychiatry 2005, 162:656-662

32. Golder SA, Macy MW: Diurnal and seasonal mood vary with work, sleep, and daylength across diverse cultures. Science 2011, 333:1878-1881.

33. Espiritu RC, Kripke DF, Ancoli-Israel S, Mowen MA, Mason WJ, Fell RL, Klauber MR, Kaplan OJ: Low illumination experienced by San Diego adults: association with atypicaldepressive symptoms. Biol Psychiatry 1994, 35:403-407.

34. Kripke DF: Light treatment for nonseasonal depression: speed, efficacy, and combined treatment. J Affect Disord 1998, 49:109-117.

35. Tuunainen A, Kripke DF, Endo T: Light therapy for non-seasonal depression. Cochrane Database Syst Rev 2004, 2:CD004050

36. Kohyama J: Sleep health and asynchronization. Brain Dev 2011, 33:252-259.

37. Phipps-Nelson J, Redman JR, Dijk DJ, Rajaratnam SM: Daytime exposure to bright light, as compared to dim light, decreases sleepiness and improves psychomotor vigilance performance. Sleep 2006, 26:695-700.

38. Ancoli-Israel S, Rissling M, Trofimenko V, Natarajan L, Parker B, Lawton S, Desan P, Liu L: Light treatment prevents fatigue in women undergoing chemotherapy for breast cancer. Support Care Cancer 2011. Jun 11[Epub ahead of print].

39. Rastad C, Ulfberg J, Lindberg P: Improvement in fatigue, sleepiness, and health-related quality of life with bright light treatment in persons with seasonal affective disorder and subsyndromal SAD. Depress Res Treat 2011, 2011:543906

40. Salgado-Delgado R, Osorio A, Saderi N, Escobar C: Disruption of circadian rhythms: a crucial factor in the etiology of depression. Depress Res Treat 2011, 2011:1-9.

41. Kim YK, Hur JW, Kim KH, Oh KS, Shin YC: Prediction of postpartum depression by sociodemographic, obstetric and psychological factors: a prospective study. Psychiatry Clin Neurosci 2008, 62:331-340.

42. Sylvenm SM, Papadopoulos FC, Olovsson M, Ekselius L, Poromaa IS, Skalkidou A: Seasonality patterns in postpartum depression. Am J Obstet Gynecol 2011, 204:e1-e6

43. Wang EJ, Kripke DF, Stein MT, Parry BL: Measurement of illumination exposure in postpartum women. BMC Psychiatry 2003, 3:1-7

44. Lewy AJ: Circadian misalignment in mood disturbances. Curr Psychiatry Rep 2009, 11:459-465.

45. Parry BL, Meliska CJ, Sorenson DL, Lopez AM, Martinez LF, Nowakowski S, Elliott JA, Hauger RL, Kripke DF: Plasma melatonin circadian rhythm disturbances during pregnancy and postpartum in depressed women and women with personal or family histories of depression. Am J Psychiatry 2008, 165:1551-1558.

46. Silverman ME, Loudon H, Liu X, Mauro C, Leiter G, Goldstein MA: The neural processing of negative emotion postpartum: a preliminary study of amygdala function in postpartum depression. Arch Womens Ment Health 2011, 14:355-359.

47. Silverman ME, Loudon H, Safier M, Protopopescu X, Leiter G, Liu X Goldstein M: Neural dysfunction in postpartum depression: an fMRI pilot study. CNS Spectr 2007, 12:853-862

48. Leibenluft $\mathrm{E}$, Yonkers KA: The ties that bind: maternal-infant interactions and the neural circuitry of postpartum depression. Am J Psychiatry 2010, 167:1373-1380.
49. Swain JE: Baby stimuli and the parent brain: functional neuroimaging of the neural substrates of parent-infant attachment. Psychiatry 2008, 5:28-36.

50. Baïlara K, Henry C, Lestage J, Launay J, Parrot F, Swendsen J, Sutter AL, Roux D, Dallay D, Demotes-Mainard J: Decreased brain tryptophan availability as a partial determinant of post-partum blues. Psychoneuroendocrinology 2006, 31:407-413.

51. Kammerer M, Taylor A, Glover V: The HPA axis and perinatal depression: a hypothesis. Arch Womens Ment Health 2006, 9:187-196.

52. Lokuge S, Frey BN, Foster JA, Soares CN, Steiner M: Depression in women: windows of vulnerability and new insights into the link between estrogen and serotonin. J Clin Psychiatry 2011, 72:e1563-e1569.

53. Pompili M, Serafini G, Innamorati M, Möller-Leimkühler AM, Giupponi G, Girardi P, Tatarelli R, Lester D: The hypothalamic-pituitary-adrenal axis and serotonin abnormalities: a selective overview for the implications of suicide prevention. Eur Arch Psychiatry Clin Neurosci 2010, 260:583-600.

54. Mitchell C, Notterman D, Brooks-Gunn J, Hobcraft J, Garfinkel I, Jaeger K, Kotenko I, McLanahan S: Role of mother's genes and environment in postpartum depression. Proc Natl Acad Sci USA 2011, 108:8189-8193.

55. Moses-Kolko EL, Wisner KL, Price JC, Berga SL, Drevets WC, Hanusa BH, Loucks TL, Meltzer CC: Serotonin 1A receptor reductions in postpartum depression: a positron emission tomography study. Fertil Steril 2008, 89:685-692.

56. Logsdon MC, Wisner K, Sit D, Luther JF, Wisniewski SR: Depression treatment and maternal functioning. Depress Anxiety 2011, 28:1020-1026.

57. Misri S, Reebye P, Corral M, Mills L: The use of paroxetine and cognitive behavioral therapy in postpartum depression and anxiety:a randomized controlled trial. J Clin Psychiatry 2004, 65:1236-1241.

58. Neumeister A: Tryptophan depletion, serotonin, and depression: where do we stand? Psychopharmacol Bull 2003, 37:99-115.

59. Bell CJ, Hood SD, Nutt DJ: Acute tryptophan depletion. Part II: clinical effects and implications. Aust N Z J Psychiatry 2005, 39:565-574.

60. aan het Rot M, Benkelfat C, Boivin DB, Young SN: Bright light exposure during acute tryptophan depletion prevents a lowering of mood in mildly seasonal women. Eur Neuropsychopharmacol 2008, 18:14-23.

61. Ahokas A, Kaukoranta J, Wahlbeck K, Aito M: Estrogen deficiency in severe postpartum depression: successful treatment with sublingual physiologic 17beta-estradiol: a preliminary study. J Clin Psychiatry 2001, 62:332-336.

62. Grigoriadis S, Kennedy SH: Role of estrogen in the treatment of depression. Am J Ther 2002, 9:503-509.

63. Kripke DF, Elliott JA, Youngstedt SD, Parry BL, Hauger RL, Rex KM: Weak evidence of bright light effects on human LH and FSH. $J$ Circadian Rhythms 2010, 8:1-9.

64. Lee KA, Gay CL: Sleep in late pregnancy predicts length of labor and type of delivery. Am J Obstet Gynecol 2004, 191:2041-2046.

65. Naghi I, Keypour F, Ahari SB, Tavalai SA, Khak M: Sleep disturbance in late pregnancy and type and duration of labour. J Obstet Gynaecol 2011, 31:489-491.

66. Pires GN, Andersen ML, Giovenardi M, Tufik S: Sleep impairment during pregnancy: possible implications on mother-infant relationship. Med Hypotheses 2010, 75:578-582.

67. Chang JJ, Pien GW, Duntley SP, Macones GA: Sleep deprivation during pregnancy and maternal and fetal outcomes: is there a relationship? Sleep Med Rev 2009, 14:107-114.

68. Fisher JR, Feekery CJ, Rowe-Murray HJ: Nature, severity, and correlates od psychological distress in women admitted to a private mother-baby unit. J Paediatr Child Health 2002, 38:140-145.

69. Dennis $C L$, Ross L: Relationships among infant sleep patterns, maternal fatigue, and development of depressive symptomology. Birth 2005, 32:187-193.

70. Field T, Diego M, Hernandez-Reif M, Figueiredo B, Schanberg S, Kuhn C: Sleep disturbances in depressed pregnant women and their newborns. Infant Behav Dev 2007, 30:127-133.

71. Goyal D, Gay CL, Lee KA: Patterns of sleep disruptions and depressive symptoms in new mothers. J Perinat Neonatal Nurs 2007, 21:123-129.

72. Huang SM, Carter A, Guo JL: A comparison of sleep and daytime sleepiness in depressed and non-depressed mothers during the early postpartum period. J Nursing Research 2004, 12:287-295.

73. Shirani A: St Louis EK: Illuminating rationale and uses for light therapy. $J$ Clin Sleep Med 2009, 5:155-163. 
74. Badia P, Myers B, Boecker M, Culpepper J, Harsh J: Bright light effects on body temperature, alertness, EEG, and behavior. Physiol Behav 1991, 50:583-588

75. Vandewalle G, Balteau E, Phillips C, Degueldre C, Moreau V, Sterpenich V, Albouy G, Darsaud A, Desseilles M, Dang-Vu TT, Peigneux P, Luxen A, Dijk DJ, Maquet P: Daytime light exposure dynamically enhances brain responses. Curr Biol 2006, 16:1616-1621.

76. Oren DA, Wisner KL, Spinelli M, Epperson CN, Peindl KS, Terman JS, Terman M: An open trial of morning light therapy for treatment of antepartum depression. Am J Psychiatry 2002, 159:666-669.

77. Wirz-Justice A, Bader A, Frisch U, Stieglitz RD, Alder J, Bitzer J, Hösli I, Jazbec S, Benedetti F, Terman M, Wisner KL, Riecher-Rössler A: A randomized, doubleblind, placebo-controlled study of light therapy for antepartum depression. J Clin Psychiatry 2011, 72:986-993.

78. Corral M, Kuan A, Kostaras D: Bright light therapy's effect on postpartum depression. Am J Psychiatry 2000, 157:303-304.

79. Corral M, Wardrop AA, Zhang H, Grewal AK, Patton S: Morning light therapy for postpartum depression. Arch Womens Ment Health 2007, 10:221-224.

80. Austin M, Hadzi-Pavlovic D, Priest S, Reilly N, Wilhelm K, Saint K, Parker G: Depressive and anxiety disorders in the postpartum period: how prevalent are they and can we improve their detection? Arch Women Ment Health 2010, 13:395-401.

81. Youngstedt SD, Kripke DF: Does bright light have an anxiolytic effect? An open trial. BMC Psychiatry 2007, 30:62.

doi:10.1186/1880-6805-31-15

Cite this article as: Crowley and Youngstedt: Efficacy of light therapy for perinatal depression: a review. Journal of Physiological Anthropology 2012 31:15.

\section{Submit your next manuscript to BioMed Central and take full advantage of:}

- Convenient online submission

- Thorough peer review

- No space constraints or color figure charges

- Immediate publication on acceptance

- Inclusion in PubMed, CAS, Scopus and Google Scholar

- Research which is freely available for redistribution 